\title{
THE EFFECT OF 'MASKING' ON PICTURE NAMING
}

\author{
Keith R Laws ${ }^{1}$, Verity C Leeson ${ }^{1}$ and Tim M Gale ${ }^{2,3}$ \\ $\left({ }^{1}\right.$ Department of Psychology, London Guildhall University, UK; ${ }^{2}$ Departments \\ of Computer Science and Psychology, University of Hertfordshire, UK; \\ ${ }^{3}$ Queen Elizabeth Hospital, Welwyn Garden City, UK)
}

\begin{abstract}
It is frequently assumed that because compared to nonliving things, living things are less familiar, have lower name frequency, and are more visually complex, this makes them more difficult to name by patients and normal subjects. This has also been implicitly accepted as an explanation for the greater incidence of living thing disorders. Patient studies do not, however, typically contain any premorbid data and so, we do not know that the same variables would have necessarily predicted their 'normal' performance. To examine this issue, we measured picture-naming latencies in normal subjects presented with unmasked and masked versions of the same line drawings. In accord with other recent studies, living things were named faster than nonliving things. Furthermore, contrary to some theories of category naming, the living thing advantage persisted regardless of whether stimuli were undegraded, degraded or the density of degradation. Finally, multiple simultaneous regression analyses showed that one visual variable (Euclidean Overlap) and one linguistic variable (Age of Acquisition) predicted naming latencies across all masked and unmasked conditions. Other variables either had no predictive value (Contour Overlap; Name Frequency; Category); predicted only high masking (Visual Complexity; Familiarity), or normal and low masking (Number of Phonemes). These findings imply that the more commonly documented deficits for living things do not reflect an exaggeration of the normal profile (be it with masked or unmasked stimuli) or the influence of the same variables that affect normal naming.
\end{abstract}

Key words: euclidean overlap, age of acquisition, reaction time, category specificity

\section{INTRODUCTION}

Picture naming difficulties have been extensively investigated in order to determine the underlying variables that contribute toward such problems. Typically, such studies have examined the role of visually based variables (e.g. visual complexity, contour overlap, imagibility) and linguistically based variables (e.g. name frequency, age of acquisition, number of phonemes/syllables, familiarity). Many of these variables are highly correlated (Nickels and Howard, 1995) and so, studies have typically used multiple regressions to uncover predictor variables and their relative and independent contributions for various clinical populations (see Ellis et al., 1996; Hirsch and Funnell, 1995; Nickels and Howard, 1995).

Similarly, attempts to account for category-specific deficits have attempted to relate apparent category effects back to variables that systematically differ between living and nonliving things. For example, compared to nonliving things, living items have lower familiarity, greater visual complexity and lower name 
frequency (Stewart et al., 1992; Funnell and Sheridan, 1992). Some also argue that living things have greater within category visual crowding i.e. are structurally more similar (Humphreys et al., 1988; Gaffan and Heywood, 1993; though see Laws, 2001; Laws and Gale, 2002; Laws et al., in press). Such accounts suggest that category deficits (typically for living things) reflect an exaggeration of the 'normal tendency' i.e. to process more slowly items that are less familiar or frequently named, and images with greater visual complexity or visual crowding. Nevertheless, recent studies of normal subjects have reported that the reverse is true when items are matched across category for artefactual variables (see Laws et al., in press; Laws, 1999, 2000; Laws and Neve, 1999).

A recent attempt has been made to reconcile the two approaches by suggesting that task demands may influence whether living or nonliving advantages occur for normal subjects (see Gerlach, 2001). Gerlach has suggested that Laws and Neve (1999) used degraded viewing conditions and this puts greater reliance on global visual processing of pictures which ultimately benefits living things; by contrast, Humphreys et al. (1988) used undegraded conditions where local information may be more fully processed and this benefits processing of nonliving things. It is true that we have shown that normals subjects show an advantage for naming living things in degraded presentation (speeded presentation: Laws and Neve, 1999; naming-to-deadline: Laws, 2000); however, we have shown the same in undegraded conditions (Laws, 1999, in press). It does remain possible that different paradigms, subjects and stimuli influenced the results, so the current study allows a direct test of this hypothesis.

It is rare for patient studies of category specific deficits to present longitudinal naming data and even rarer that they are in a position to include any pre-morbid data. Therefore, although the well-documented predictor variables may account for the pattern of naming deficit after brain injury, it is not possible to show that the same measures would have also predicted their 'normal' or 'optimal' naming accuracy. It would therefore be informative to know if: the same predictor variables account for normal and impaired naming; some variables are only influential for normal or impaired performance; or differences in severity of impairment may reflect different variables (e.g. Gonnerman et al., 1997).

As an analogue for some aspects of agnosia, we used 'masking' to degrade line drawings from the Snodgrass and Vanderwart corpus to simulate a gradual degradation in pictorial input. Naming latencies were then compared across unmasked and (low and high density) masked stimuli in the same normal participants and those variables that predicted naming latencies for the masked and unmasked stimuli were examined.

\section{MAterials AND Methods}

\section{Subjects}

Twenty subjects ( 8 female, 12 male) participated in this study. Their mean age was 25.75 years $(S D=5.75$ : range $22-43)$. None of the subjects had seen the pictures before and all had normal or normal-to-corrected vision. English was the first language in all participants. 


\section{Stimuli}

One hundred and twenty stimuli (38 living and 82 non-living things: see appendix for full list) were selected from the Snodgrass and Vanderwart (1980) corpus of line drawings. Each picture was standardised for size with a maximum vertical and horizontal extent of $7.6 \mathrm{~cm}$ and was presented on a computer screen, viewed at a distance of $30 \mathrm{~cm}$.

The pictures were chosen to reflect a wide range of values for: (a) familiarity (mean = $3.25 \pm .87$ : range $=1.52-4.82)$, name frequency $($ mean $=34.24 \pm 64$ : range $=0-352)$ and visual complexity $($ mean $=3.63 \pm .75$ : range $=1.15-4.78)$ - each had a normal distribution and a skew value of $<0.1$ (see Ellis et al., 1996); and (b) a range of items from major subcategories including animals $(n=16)$, birds $(n=5)$, clothes $(n=12)$, fruit $(n=5)$, furniture $(n=10)$, music instruments $(n=8)$, tools $(n=10)$, transport $(n=8)$, vegetables $(n=7)$, as well as miscellaneous items $(n=27)$ e.g. snowman, mountain, tree and flag (see Appendix for full list).

The living things had lower familiarity (2.99 vs. 3.38: $\mathrm{t}=-2.3, \mathrm{p}=.023)$, lower name frequency $(\log .95$ vs. $1.24: \mathrm{t}=-2.19, \mathrm{p}=.03)$; and greater visual complexity (3.18 vs. 2.89: $\mathrm{t}=1.99, \mathrm{p}=.05)$ than the nonliving things. This is typical of living and nonliving items from this corpus (see Snodgrass and Vanderwart, 1980; Funnell and Sheridan, 1992; Stewart et al., 1992).

Using a graphics-editing program, two 'peppery' masks were created for each stimulus (one of lower and one of higher density masking). The mask consisted of a random-noise filter covering 10 and 20 percent of each picture with pixels (see Figure 1); these levels of interference were derived from trial-and-error using the constraint that every stimulus should still be visible at $20 \%$ (cf. Vecera and Gilds, 1998).

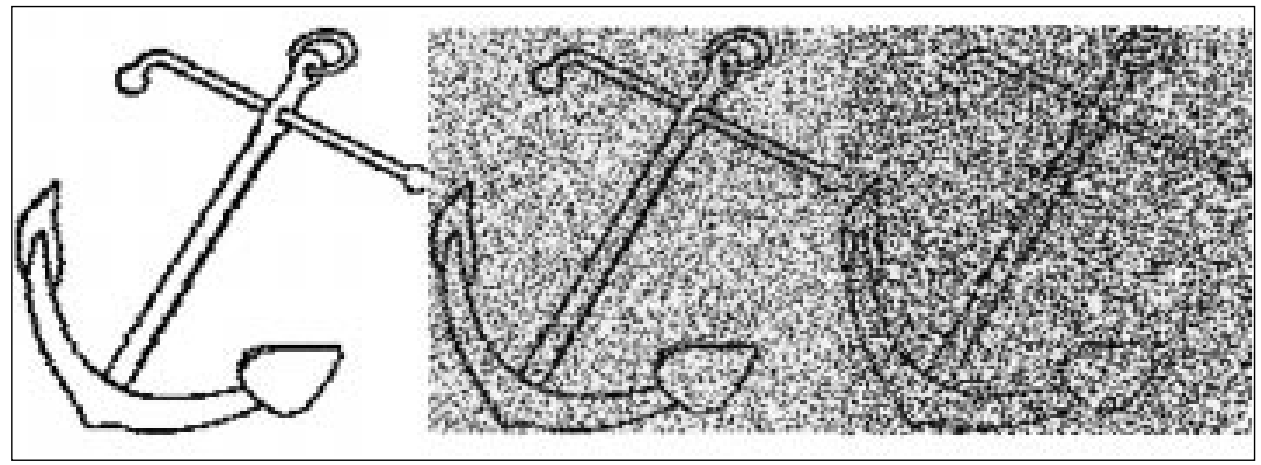

Fig. 1 - Example of unmasked, low density (10\%) and high density mask (20\%).

\section{Procedure}

The 120 items were divided into three blocks and each block contained all three variants of the same item (i.e. 120 stimuli per block). Subjects were tested on all three blocks (i.e. each subject named 360 pictures), separated by 10 minutes to avoid tiredness or lack of concentration. The pictures were presented on an Apple Macintosh hi-resolution monitor using the Superlab ${ }^{\mathrm{TM}}$ program. Subjects were asked to name each item as it appeared on the screen and the latency of their response was recorded using a voice key. A blank white screen appeared between each presented picture for $1000 \mathrm{~ms}$.

Although normal participants would be familiar with the overwhelming majority of referents in the Snodgrass and Vanderwart corpus, they would not be familiar with their specific visual representations. The pictures were therefore initially presented in their unmasked state to ensure that subjects became familiar with the specific representations. Critically, the unmasked condition also provided an analogue 'unimpaired' baseline. Subjects then saw the $20 \%$ masked and finally the $10 \%$ masked stimuli. Comparisons 
between $10 \%$ and $20 \%$ masking therefore reflected degradation of input rather than lack of familiarity with the specific pictures. In other words, subjects had previously seen the degraded stimuli in an undegraded state and had accurately named them (this also provided data on items that could potentially be more problematic).

\section{RESULTS}

Subjects made less than $1 \%$ errors so these were not separately analysed. The unmasked RTs were not significantly different from (both $\mathrm{t}<1, \mathrm{p}>.05$ ) and were highly correlated with those detailed by Snodgrass and Yuditsky (1996: $\mathrm{r}=.63, \mathrm{p}<.001)$ and Barry et al. $(1997: \mathrm{r}=.68, \mathrm{p}<.001)$. Hence, the RTs are typical of those recorded in two other studies.

All analyses were made across both items $\left(\mathrm{F}_{1}\right)$ and subjects $\left(\mathrm{F}_{2}\right)$ comparing $10 \%$ and $20 \%$ masking conditions. These revealed a significant main effect for masking $\left(\mathrm{F}_{1}=105.49\right.$; d.f. $=1,118 ; \mathrm{p}<.001 ; \mathrm{F}_{2}=43.16$; d.f. $\left.=1,19 ; \mathrm{p}<.001\right)$. There was a significant main effect for category across subjects (see Figure 2), and although the same pattern appeared across items it failed to reach significance $\left(\mathrm{F}_{1}=0.57\right.$; d.f. $=1,118 ; \mathrm{p}=.45 ; \mathrm{F}_{2}=4.85 ;$ d.f. $\left.=1,19 ; \mathrm{p}=.04\right)$. There was no interaction for masking by category $\left(F_{1}=0.13\right.$; d.f. $=1,118$; $\mathrm{p}=.72 ; \mathrm{F}_{2}=0.17 ;$ d.f. $\left.=1,19 ; \mathrm{p}=.68\right)$.

A small number of items produced outlying RTs [< 1\%]: Unmasked (flute, chisel, swing); $10 \%$ mask (flute); $20 \%$ mask (sledge, mouse). Reanalysis after removing these items made no difference to the results. Although we included musical instruments, these did not account for the slower latencies to nonliving things. Only one MI (flute) appeared in the slowest 20 RTs for nonliving items and removing the RTs for all musical instruments made no difference to the results.

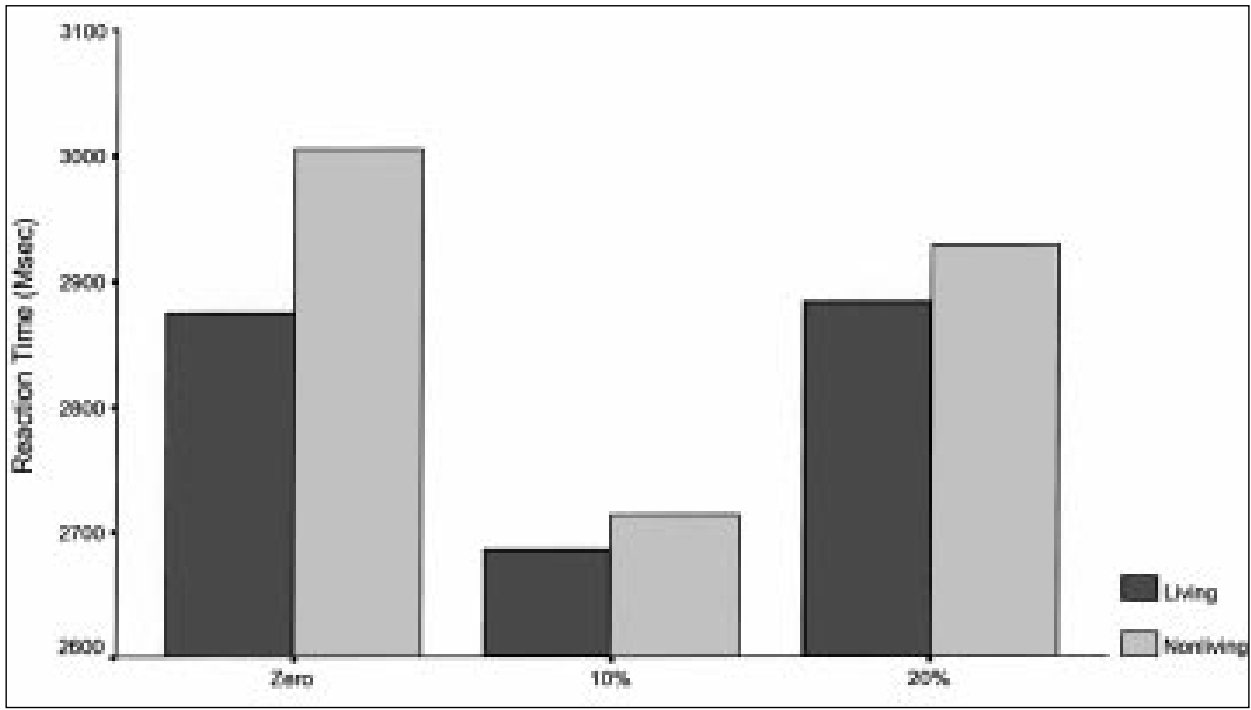

Fig. 2 - Mean naming latencies to living and nonliving things in masked and unmasked conditions. 
Finally, while latencies became faster (were primed) with repeated exposure, there was no evidence that priming interacted with category $\left(\mathrm{F}_{1}=0.002\right.$; d.f. $=1,118$; $\mathrm{p}=.96 ; \mathrm{F}_{2}=1.01 ;$ d.f. $\left.=1,19 ; \mathrm{p}=.37\right)$.

\section{Regression Analyses}

Simultaneous regression analyses were used to determine the significant predictors of naming latencies for each set of RTs i.e. unmasked, $10 \%$ and $20 \%$ mask. The following variables were used as predictors because of: (a) their availability for the Snodgrass and Vanderwart corpus; (b) their perceived theoretical importance in picture naming; and (c) to cover a range of visual, semantic and lexical processing variables:

(1) Age of acquisition (AA): objective age of acquisition data in 280 children (from Morrison et al., 1997). The age of acquisition of each item was taken to be the age at which $75 \%$ or more of the children could name the picture.

(2) Name frequency: log-transformed Kuçera-Francis name frequency.

(3) Number of phonemes.

(4) Familiarity: from Snodgrass and Vanderwart (1980).

(5) Visual Complexity (VC): from Snodgrass and Vanderwart (1980).

(6) Euclidean Overlap (EO): a measure of the pixel-by-pixel overlap within subcategories of pictures from the Snodgrass and Vanderwart corpus (Laws and Gale, 2002). This reflects the euclidean distance between all pairs of pictures in each subcategory (e.g. dog and cat; dog and cow; cow and cat; cow and dog). This is calculated by comparing the value for each pixel (i.e. 1 or 0 ) and then subtracting the value in picture A from that of picture $\mathrm{B}$. The difference is squared and summed for all 65,536 pixels in each array. The EO between the two pictures is the square root of the sum of squared differences.

(7) Contour Overlap (CO): a measure of the gross contour overlap within picture subcategories from the Snodgrass and Vanderwart corpus. It is derived by overlaying a grid on each item with every other item and calculating the average overlap between pictures as a function of the amount of contour in each picture at a gross visible level (Humphreys et al., 1988).

(8) Category (dummy variable: living and nonliving).

At zero $\left(\mathrm{r}^{2}=.42\right)$, the following were significant: AA $(\mathrm{t}=5.51, \mathrm{p}=.001)$; EO $(\mathrm{t}=-3.13, \mathrm{p}=.003)$; phonemes $(\mathrm{t}=2.68, \mathrm{p}=.01)$. At $10 \%$ masking $\left(\mathrm{r}^{2}=.30\right)$, the following were significant: phonemes $(\mathrm{t}=3.77, \mathrm{p}<.001)$; AA $(\mathrm{t}=2.89, \mathrm{p}=.005)$; EO $(\mathrm{t}=-2.13, \mathrm{p}=.037)$. Finally, at $20 \%\left(\mathrm{r}^{2}=.30\right)$, the following were significant: AA $(\mathrm{t}=4.18, \mathrm{p}<.001)$; $\mathrm{EO}(\mathrm{t}=-3.11, \mathrm{p}=.003)$; familiarity $(\mathrm{t}=3.02, \mathrm{p}=.003)$; visual complexity $(\mathrm{t}=2.72, \mathrm{p}=.008)$. No other variables reached significance. Tolerance was .6+ for all variables in all conditions - suggesting no evidence of multicollinearity.

\section{Interaction between EO, AA and Levels of Degradation}

To determine the effects of EO and AA across all levels of degradation, we compared two categorical levels of EO and AA (i.e. the top and bottom thirds 
TABLE 1

Simple Correlations between Predictor Variables (and Naming RTs)

\begin{tabular}{lcccccccc}
\hline & $\begin{array}{c}\text { Contour } \\
\text { overlap }\end{array}$ & $\begin{array}{c}\text { Euclidean } \\
\text { overlap }\end{array}$ & $\begin{array}{c}\text { Visual Familiarity } \\
\text { complexity }\end{array}$ & & & & \multicolumn{3}{c}{$\begin{array}{c}\text { Name } \\
\text { frequency }\end{array}$} & Phonemes \\
\hline CO & & -.13 & -.10 & $-.21^{*}$ & $-.44^{*}$ & .10 & -.15 & .02 \\
VO & & & $-.48^{* *}$ & .16 & $.53^{*}$ & .02 & .11 & .01 \\
VC & & & & -.14 & -.18 & .06 & -.05 & .09 \\
Familiarity & & & & & $.20^{*}$ & $-.36^{*}$ & $.39^{*}$ & -.10 \\
Category & & & & & & .16 & .21 & .00 \\
AA & .00 & .20 & .11 & $-.18^{*}$ & .12 & $.51^{* *}$ & -.14 & .07 \\
Zero & .10 & .10 & .09 & -.03 & .11 & $.30^{* *}$ & $-.28^{*}$ & $.38^{* *}$ \\
10 & .06 & .14 & $.19^{*}$ & .07 & .05 & $.28^{* *}$ & -.07 & $.25^{* *}$ \\
20 & & & & & & & & \\
\hline
\end{tabular}

** Significant at the 0.01 level (2-tailed).

* Significant at the 0.05 level (2-tailed).

TABLE 2

Regression Results Showing the Predictor Variables for the Three Naming Conditions

\begin{tabular}{lcccccccc}
\hline & $\begin{array}{c}\text { Contour } \\
\text { overlap }\end{array}$ & $\begin{array}{c}\text { Euclidean } \\
\text { overlap }\end{array}$ & $\begin{array}{c}\text { Visual } \\
\text { complexity }\end{array}$ & Familiarity Category & A of A & $\begin{array}{c}\text { Name } \\
\text { frequency }\end{array}$ & Phonemes \\
\hline Zero & $\mathrm{X}$ & $\sqrt{ }$ & $\mathrm{X}$ & $\mathrm{X}$ & $\mathrm{X}$ & $\sqrt{ }$ & $\mathrm{X}$ & $\sqrt{ }$ \\
10 & $\mathrm{X}$ & $\sqrt{ }$ & $\mathrm{X}$ & $\mathrm{X}$ & $\mathrm{X}$ & $\sqrt{ }$ & $\mathrm{X}$ & $\sqrt{ }$ \\
20 & $\mathrm{X}$ & $\sqrt{ }$ & $\sqrt{ }$ & $\sqrt{ }$ & $\mathrm{X}$ & $\sqrt{ }$ & $\mathrm{X}$ & $\mathrm{X}$ \\
\hline
\end{tabular}

$\sqrt{ }=$ Significant

$\mathrm{X}=$ Nonsignificant

on these measures) across the three levels of degradation. Repeated measures ANOVAs revealed no evidence of interaction for $\mathrm{VO}(\mathrm{F}<1)$, i.e. degradation has no greater effect on items with high than low visual overlap. By contrast, AA did interact significantly with degradation $(F=13.9$, d.f. $=76, p<.001)$, with degradation reducing the advantage of early over late acquired names similarly at both levels of degradation).

\section{DISCUSSION}

Regardless of whether unmasked, masked or the density of masking, normal subjects named living things more quickly than nonliving things. This accords with our previous documentation of a normal advantage for naming living things with degraded (Laws and Neve, 1999; Laws, 2000) and undegraded stimuli (Laws, 1999, in press) and extends these findings by documenting a living thing advantage across the same degraded and undegraded stimuli in the same subjects. The consistency between these studies and the current one makes it unlikely that the living thing advantage is in any way specific to (or an artefact of) this repeated measure paradigm. Finally, regression analyses revealed that only two of eight variables consistently predicted naming latencies across the three conditions: a visual variable (Euclidean Overlap: EO) and a lexical variable (Age of Acquisition: AA).

Masking evidently provides a closer model for factors affecting how stored representations are addressed (i.e. a bottom-up or input deficit) rather than those 
associated with the damage to stored representations themselves (see Laws and Gale, 2002). The results are, however, comparable with previous studies of category specificity in normal subjects because all have used variants of this approach, largely perhaps because stored representations are not open to manipulation (Gaffan and Heywood, 1993; Laws and Neve, 1999; Laws, 2000; Gerlach, 2001) ${ }^{1}$.

Clearly, the naming advantage for living things cannot be explained by recourse to variables, such as familiarity, visual complexity, and name frequency, which have been shown to be important in category deficits (Funnell and Sheridan, 1992; Stewart et al., 1992). Indeed, in the current study, all three were poor predictors, none predicted naming latencies to 'normal' unmasked stimuli, and if anything, would predict the reverse pattern (since the living things had significantly lower familiarity, lower name frequency and greater visual complexity than the nonliving things). While it is widely accepted that VC and familiarity are important factors in the naming of patients with category deficits, these two variables predicted naming only with dense masking (20\%) and this might be interpreted to provide some correspondence between the effects of dense masking and actual impairment. Nevertheless, inconsistencies in predictor variables highlight the possibility that normal and 'impaired' naming are not influenced by the same variables (or combinations of variables).

The advantage for naming living things in unmasked, and especially in masked, conditions is incompatible with the notion that living things are more visually crowded than nonliving things (e.g. Gaffan and Heywood, 1993; Humphreys et al., 1988). These notions of visual crowding could be extrapolated to predict that masking should increase a normal difficulty with the recognition and naming of living things. We would, however, argue for the converse, i.e. that nonliving things actually show greater visual crowding (as measured by visual overlap), that this actually creates greater processing disadvantages for nonliving things (Laws, 2001; Laws and Gale, 2002; Laws et al., in press) ${ }^{2}$, and proved to be the only significant visually-based predictor of naming across all conditions.

Similarly, our findings also oppose the recent proposal relating task demands to whether normal subjects show a living or nonliving advantage (Gerlach, 2001). This notion suggests that degraded viewing conditions encourage global picture processing and that this benefits living things (believed to be structurally similar); by contrast, in undegraded conditions where local information may receive more processing, nonliving things (believed to be structurally dissimilar) have an advantage. Nevertheless, the advantage for living things documented here persisted both across undegraded and across two levels of degraded stimuli.

The current study confirms previous reports that when compared to AA,

\footnotetext{
${ }^{1}$ It should also be noted that these accounts of category naming deficits do not draw a distinction between deficits that arise from access or storage problems. Indeed, some blur the distinction between the access and storage of representations. For example, measures relating to the appearance of items (e.g. structural similarity) are derived from the stimuli and so, reflect input variables, but they are also spoken about as aspects of the stored representational information (e.g. Humphreys et al., 1988).

${ }^{2}$ We would add an important caveat - although the vast majority of category-specific studies (Laws and Gale, 2002, estimated over $90 \%$ between $1988-2000[\mathrm{n}=50]$ ) have used these stimuli - this interpretation applies only to line drawings and different outcomes may occur with other stimuli such as photographs (Gale et al., 2001).
} 
name frequency is a poor predictor of naming (Morrison et al., 1992; Laws, 2000). Not only was AA a consistent predictor of naming, but it also interacted with masking such that the latency advantage for early over late AA items was diminished with masking. Given that AA affects lexical processing (Barry et al., 1997), this interaction is consistent with the notion that picture naming processes occur in cascade (see Humphreys et al., 1988). In other words, AA appears to exert a top-down influence on the naming process before visual processing is complete. Turning to the level of visual processing, EO, a measure of pixel-bypixel visual overlap was the only other significant predictor at all levels. That EO showed no interaction with masking accords with our previous suggestions that EO is a bottom-up visual variable (Laws and Gale, 2002; Laws et al., in press) i.e. EO appears to have a bottom-up additive effect on the naming process.

By contrast with AA, EO is a new variable that is only beginning to be examined in studies of picture naming and category specificity; however, our recent work does suggest that it is an important variable. Not only does EO predict naming latencies for degraded and undegraded stimuli, but we have found that it also correlates significantly with naming errors made by normal subjects (Laws and Gale, in press). Additionally, EO is the only visually-based variable that clearly separates nonliving things with high overlap (and includes body parts) from living things with low overlap (and includes musical instruments: Laws and Gale, 2002; Laws, in press; Laws et al., in press) ${ }^{3}$. So, both AA and EO exert consistent effects on naming, but from top-down and bottom-up ends of the picture naming process respectively. We suggest that, in addition to AA, future studies should consider the influence of EO on both category deficits and picture naming per se.

Acknowledgements. We would like to thank Professor Glyn Humphreys for kindly providing his Contour Overlap data. We would also like to thank Henry Buchtel and two anonymous reviewers for their helpful and thoughtful comments. Thanks also to Ann Hagues for helping prepare the stimuli. This research was part supported by LGU and UH.

\section{REFERENCES}

BARry C, Morrison CM and Ellis AW. Naming the Snodgrass and Vanderwart pictures: Effects of age of acquisition, frequency and name agreement. Quarterly Journal of Experimental Psychology, 50A: 560-585, 1997.

Ellis AW, LUM C and LAMBON RalPh MA. On the use of regression techniques for the analysis of single case aphasic data. Journal of Neurolinguistics, 9: 165-174, 1996.

FUNNELL E and SHERIDAN J. Categories of knowledge? Unfamiliar aspects of living and nonliving things. Cognitive Neuropsychology, 9: 135-153, 1992.

GAFFAN D and HEYwOOD CA. A spurious category-specific visual agnosia for living things in normal human and nonhuman primates. Journal of Cognitive Neuroscience, 5: 118-128, 1993.

GALE TM, Done DJ and FrAnK RJ. Visual crowding and category-specific deficits for pictorial stimuli: A neural network model. Cognitive Neuropsychology, 18: 509-550, 2001.

GERLACH C. Structural similarity causes different category-effects depending on task characteristics. Neuropsychologia, 39: 895-900, 2001.

Gonnerman LM, Anderson AS, Devlin JT, Kempler D and Seidenberg MS. Double dissociation of semantic categories in Alzheimer's disease. Brain and Language, 57: 254-279, 1997.

\footnotetext{
${ }^{3}$ A similar Euclidean metric has recently been used in a different context to accurately describe the similarity between dot patterns (Smith and Minda, 2001) and was found to correlate strongly with subjective comparisons of similarity.
} 
HIRSH KW and FunNELl E. Those old, familiar things: Age of acquisition, familiarity and lexical access in progressive aphasia Journal of Neurolinguistics, 9: 23-32, 1995.

Humphreys GW, Riddoch J and Quinlan PT. Cascade processes in picture identification. Cognitive Neuropsychology, 5: 67-103, 1988.

LAWS KR. Gender affects latencies for naming living and nonliving things. Cortex, 35: 729-733, 1999.

LAWS KR. Category-specific naming errors in normal subjects: The influence of evolution and experience. Brain and Language, 75: 123-133, 2000.

LAWS KR. What is structural similarity and is it greater in living things? Behavioural and Brain Sciences, 24: 486-487, 2001a.

LAWS KR. Category-specific naming and modality-specific imagery. Brain and Cognition (in press).

LAWS KR and GALE TM. Category-specific naming and the 'visual' characteristics of line-drawn stimuli. Cortex, 38: 7-21, 2002.

LAWS KR, GALE TM, FRANK RJ and DAVEY N. Visual similarity is greater for line drawings of nonliving than living things: The importance of musical instruments and body-parts. Brain and Cognition (in press).

LAWS KR and NEVE C. A 'normal' category-specific advantage for naming living things. Neuropsychologia, 37: 1263-1269, 1999.

Morrison CM, CHAPPELl TD and ElLIS AN. Acte of acquisition norms for a large set of object names and their relation to adult estimates and other variables. Quarterly Journal of Experimental Psychology 50A: 528-559, 1997.

Morrison CM, Ellis AW, and Quinlan PT. Age of acquisition, not word frequency, affects object naming, not object recognition. Memory and Cognition, 20: 705-714, 1992.

NiCKELS L and HowARD D. Aphasic naming - what matters? Neuropsychologia, 33: 1281-1303, 1995.

SMITH JD and MiNDA JP. Journey to the center of the category: The dissociation in amnesia between categorization and recognition. Journal of Experimental Psychology: Learning, Memory, and Cognition, 27: 984-1002, 2001.

SNODGRASS JG and VANDERWART M. A standardized set of 260 pictures: Norms for name agreement, image agreement, familiarity and visual complexity. Journal of Experimental Psychology: Human Learning and Memory, 6: 174-215, 1980.

SNODGRASS JG and YUdiTSKY T. Naming times for the Snodgrass and Vanderwart pictures. Behavior Research Methods, Instruments and Computers, 28: 516-536, 1996.

STEWART F, PARKIN AJ and HunKIN NM. Naming impairments following recovery from herpes simplex encephalitis: Category-specific? Quarterly Journal of Experimental Psychology, 44A: 261-284, 1992.

VECERA SP and GILDS KS. What processing is impaired in apperceptive agnosia? Evidence from normal subjects. Journal of Cognitive Neuroscience, 10: 568-580, 1998.

Dr Keith R Laws, Department of Psychology, London Guildhall University, Calcutta House, Old Castle Street, London E1 7NT, UK. E-mail: klaws@lgu.ac.uk.

(Received 10 May 2001; reviewed 15 July 2001; revised 9 August 2001; accepted 24 August 2001; Action Editor: Henry A. Buchtel) 
APPENDIX 1

RTs in Each Condition for Each Item

\begin{tabular}{|c|c|c|c|c|c|c|c|}
\hline Item & Zero & $10 \%$ & $20 \%$ & Item & Zero & $10 \%$ & $20 \%$ \\
\hline Animals & & & & Vase & 752.0 & 673.4 & 775.5 \\
\hline Bear & 806.9 & 685.8 & 729.2 & Insects & & & \\
\hline Cat & 575.6 & 664.9 & 666.7 & Beetle & 761.1 & 642.5 & 685.5 \\
\hline Dog & 631.4 & 630.9 & 712.8 & Butterfly & 687.2 & 685.5 & 702.9 \\
\hline Donkey & 796.5 & 693.2 & 740.1 & Caterpillar & 784.0 & 759.5 & 765.7 \\
\hline Fish & 617.7 & 642.3 & 681.9 & Kitchen utensils & & & \\
\hline Frog & 611.8 & 688.4 & 701.9 & Fork & 714.7 & 654.7 & 722.8 \\
\hline Goat & 867.1 & 639.3 & 631.6 & Glasses & 693.5 & 614.1 & 705.6 \\
\hline Horse & 649.8 & 626.5 & 677.5 & Kettle & 680.7 & 716.6 & 740.7 \\
\hline Monkey & 695.5 & 625.8 & 641.2 & Rolling & 684.3 & 667.4 & 749.4 \\
\hline Mouse & 711.3 & 705.2 & 893.3 & Stove & 803.8 & 696.4 & 828.4 \\
\hline Pig & 637.5 & 641.1 & 789.5 & Toaster & 833.2 & 706.6 & 732.5 \\
\hline Seal & 894.7 & 722.8 & 779.4 & Musical instrum & ents & & \\
\hline Snail & 738.5 & 670.7 & 665.6 & Bell & 628.2 & 650.9 & 605.3 \\
\hline Snake & 697.8 & 634.9 & 697.3 & Drum & 747.5 & 644.6 & 659.6 \\
\hline Squirrel & 791.9 & 707.6 & 734.0 & Flute & 1133.6 & 849.1 & 842.7 \\
\hline Turtle & 707.2 & 700.7 & 674.6 & Guitar & 817.8 & 685.1 & 697.5 \\
\hline Birds & & & & Harp & 733.2 & 650.7 & 672.5 \\
\hline Bird & 711.7 & 644.5 & 711.0 & Piano & 719.8 & 721.2 & 746.9 \\
\hline Chicken & 797.5 & 674.4 & 720.5 & Trumpet & 814.5 & 694.9 & 740.3 \\
\hline Duck & 771.3 & 685.3 & 731.8 & Violin & 770.9 & 717.1 & 771.7 \\
\hline Penguin & 696.4 & 628.9 & 676.3 & Tools & & & \\
\hline Swan & 766.8 & 694.9 & 720.1 & Axe & 894.0 & 668.6 & 679.1 \\
\hline Clothes & & & & Chisel & 1012.9 & 710.2 & 860.8 \\
\hline Boot & 711.2 & 644.5 & 656.3 & Hammer & 649.3 & 697.8 & 639.1 \\
\hline Coat & 890.9 & 704.7 & 747.2 & Ladder & 729.1 & 651.4 & 699.9 \\
\hline Crown & 708.3 & 769.6 & 739.6 & Nail & 819.9 & 674.9 & 697.7 \\
\hline Dress & 835.5 & 675.3 & 746.1 & Paintbrush & 824.8 & 686.3 & 811.0 \\
\hline Glove & 707.8 & 706.1 & 685.9 & Saw & 759.0 & 618.2 & 748.3 \\
\hline Hat & 602.0 & 600.4 & 644.4 & Scissors & 679.0 & 623.5 & 694.9 \\
\hline Mitten & 682.5 & 684.5 & 739.6 & Screw & 683.6 & 735.8 & 807.1 \\
\hline Necklace & 751.0 & 700.0 & 652.8 & Screwdriver & 814.7 & 725.9 & 852.5 \\
\hline Shoe & 616.1 & 613.8 & 652.9 & Toys & & & \\
\hline Skirt & 831.8 & 750.8 & 711.7 & Ball & 749.7 & 613.9 & 624.1 \\
\hline Tie & 712.6 & 652.8 & 808.8 & Kite & 746.0 & 687.2 & 721.9 \\
\hline Watch & 764.6 & 589.3 & 728.1 & Swing & 1002.4 & 684.8 & 784.8 \\
\hline Fruits & & & & Transport & & & \\
\hline Apple & 647.1 & 654.5 & 657.0 & Airplane & 684.5 & 663.0 & 743.4 \\
\hline Banana & 669.8 & 680.8 & 674.5 & Bike & 639.1 & 619.0 & 758.8 \\
\hline Grapes & 740.7 & 716.9 & 774.3 & Car & 636.3 & 652.3 & 797.4 \\
\hline Lemon & 731.3 & 661.6 & 652.7 & Helicopter & 725.7 & 643.6 & 714.8 \\
\hline Pear & 730.3 & 654.7 & 764.2 & Motorbike & 871.8 & 731.3 & 856.7 \\
\hline Furniture & & & & Pram & 717.3 & 768.2 & 763.0 \\
\hline Bed & 676.0 & 586.8 & 667.2 & Sled & 894.4 & 772.6 & 955.0 \\
\hline Chair & 640.6 & 667.7 & 694.2 & Train & 739.5 & 644.1 & 753.0 \\
\hline Clock & 722.0 & 668.6 & 728.5 & Vegetables & & & \\
\hline Lamp & 806.4 & 740.5 & 759.8 & Carrot & 636.2 & 703.6 & 730.9 \\
\hline Record player & 859.7 & 750.7 & 827.6 & Celery & 879.9 & 718.0 & 849.1 \\
\hline Stool & 795.7 & 671.6 & 763.8 & Corn & 968.9 & 719.1 & 878.6 \\
\hline Table & 707.7 & 678.4 & 677.3 & Lettuce & 842.0 & 724.8 & 878.9 \\
\hline Telephone & 784.5 & 744.4 & 788.7 & Mushroom & 674.3 & 641.9 & 736.3 \\
\hline Television & 845.7 & 744.4 & 806.8 & Onion & 789.6 & 629.5 & 666.7 \\
\hline
\end{tabular}




$\begin{array}{lccclccc}\text { Item } & \text { Zero } & 10 \% & 20 \% & \text { Item } & \text { Zero } & 10 \% & 20 \% \\ \begin{array}{c}\text { Potato } \\ \text { Miscellaneous }\end{array} & 701.9 & 720.3 & 871.2 & \text { Plug } & 867.9 & 749.0 & 848.1 \\ \text { Anchor } & 725.4 & 611.1 & 690.3 & \text { Sraffic Light } & 846.2 & 672.2 & 834.2 \\ \text { Candle } & 683.8 & 646.4 & 688.4 & \text { Flower } & 680.5 & 621.4 & 717.9 \\ \text { Cigar } & 839.7 & 717.9 & 728.2 & \text { Leaf } & 797.2 & 647.9 & 681.8 \\ \text { Church } & 743.9 & 653.1 & 721.1 & \text { Tree } & 687.7 & 631.4 & 715.2 \\ \text { Door } & 589.4 & 606.8 & 690.4 & \text { Clothes peg } & 837.6 & 694.5 & 793.7 \\ \text { Flag } & 675.3 & 629.1 & 695.8 & \text { Comb } & 674.8 & 614.5 & 680.8 \\ \text { Gun } & 752.5 & 640.0 & 714.7 & \text { Iron } & 693.4 & 722.3 & 710.9 \\ \text { Light bulb } & 730.4 & 677.5 & 648.0 & \text { Tennis racket } & 830.1 & 708.4 & 695.1 \\ \text { Barrel } & 632.2 & 653.1 & 659.7 & \text { Thimble } & 782.5 & 630.6 & 684.0 \\ \text { Bottle } & 735.7 & 723.3 & 697.6 & \text { Toothbrush } & 685.5 & 794.6 & 790.6 \\ \text { Lock } & 762.3 & 721.6 & 708.4 & \text { Umbrella } & 721.8 & 755.5 & 732.3 \\ \text { Mountain } & 862.1 & 648.0 & 704.0 & \text { Wheel } & 691.7 & 576.9 & 690.1 \\ \text { Pipe } & 725.6 & 692.7 & 781.5 & & & & \end{array}$

